\title{
Mathematical Analysis of Removal of Dissolved Acidic Gases from Aqueous Stream Using Membrane Contactor
}

\author{
Ashutosh Rawat, Gunjan K. Agrahari, Niharika Pandey, and Prashant K. Bhattacharya
}

\begin{abstract}
A mathematical analysis was performed on an acid-gas removal process applied to an aqueous feed stream using a hollow fiber membrane contactor in liquid-liquid extraction mode. Furthermore, a comparison was made between the obtained simulation results and with the earlier published experimental results. The model development is based on a process setup wherein synthetic wastewater feed solution was considered to be passing through the lumen side and later recycled back to the feed tank. On the shell side of the membrane contactor, an extractant was circulated in the counter direction. The model is developed considering radial and axial diffusion mechanisms and convection on the lumen side. Mass transfer across the pore by diffusion from Knudsen and bulk flow has also been considered. The partial differential equations obtained, were solved by converting them into a number of ordinary differential equations by using the finite difference method. The model was solved and simulated using MATLAB. The effect of various membrane contactor parameters such as the number of fibers and their effective lengths on the removal of gases have also been studied in this analysis. The simulated results obtained were observed to be in excellent agreement with the experimental results obtained for the acidic gas, $\mathrm{H}_{2} \mathrm{~S}$.
\end{abstract}

Index Terms - Waste water treatment, membrane separation, hollow fiber membrane contactor, degasification of water, modeling and simulation.

\section{INTRODUCTION}

Large amounts of dissolved acidic gases such as $\mathrm{CO}_{2}$ and $\mathrm{H}_{2} \mathrm{~S}$ are generally found in natural water reservoirs and industrial wastewater. $\mathrm{CO}_{2}$ is present in natural water reservoirs because of the respiration and photosynthesis of marine animals and plants, decay of organic substances, and dissolution of carbonate salts present at the reservoir bottoms[1]. $\mathrm{H}_{2} \mathrm{~S}$ is also present in thermal sulfur springs [2].

Industrial plants manufacturing ammonia and urea generate wastewater streams containing high $\mathrm{CO}_{2}$ contents. In general, industries that manufacture viscose rayon, paper, and pulp discharge wastewater streams containing high $\mathrm{H}_{2} \mathrm{~S}$ concentrations. Dissolved $\mathrm{H}_{2} \mathrm{~S}$ may also be found in untreated agricultural water output and in effluent streams generated from the hydrocracking of crude oil [3], [4]. Conventional processes for wastewater treatment, such as aeration, forced draft degasification, and vacuum degasification may involve high cost as these processes

Manuscript received May 31, 2013; revised July 28, 2013. The work is partially supported by Council of Scientific and Industrial Research, India; vide sponsored project sanction letter number 22(0496)/10/EMR-II.

The authors are with the Chemical Engineering Department at IIT Kanpur-208016 India (email: ashurawt@iitk.ac.in, gunjan@iitk.ac.in, pniharika23@gmail.com,pkbhatta@iitk.ac.in). require high duty equipments like blowers etc. In such cases, membrane contactor could become a viable alternative. Methods including vacuum sweep mode and gas-liquid extraction in membrane contactors may have some operational drawbacks; moreover, precise design is required to avoid loading or flooding in columns [5]. In recent years, membrane contactors have evolved as very important tool for separation. These contactors consist of a cylindrical cartridge which contains number of microporous hollow fibers constituting the lumen side of the contactor. Fibers in the membrane contactor are polymeric and can be either hydrophobic or hydrophilic. Polypropylene and polytetrafluoroethylene are the polymeric materials used for making hydrophobic membranes, which can be used for removing volatile species and gases from water.

The degasification of feed streams using membrane contactors has been studied by many researchers. $\mathrm{CO}_{2}$ removal from gas using monoethanolamine as the extractant in the membrane contactor has been studied by Bottino et al. [6], while experimental study and numerical analysis of carbon dioxide removal from water in liquid-liquid extraction mode have been performed by Agrahari et al. [7]. Keshavarz et al. [8] have presented a mathematical model for membrane contactors used for the simultaneous absorption of $\mathrm{CO}_{2}$ and $\mathrm{H}_{2} \mathrm{~S}$ from gaseous feed to diethanolamine (DEA) solution. McDermott et al. [9] studied the removal of volatile and semi-volatile organic components from water using membrane contactors in the vacuum sweep mode. More specifically, Mandowara and Bhattacharya [10] have also performed a mathematical analysis on the removal of ammonia from water using a membrane contactor in the gas-liquid mode operation, while Agrahari et al. [11] performed an experimental study of $\mathrm{H}_{2} \mathrm{~S}$ extraction from an aqueous stream where the model was developed by defining the transport of a gas molecule by adsorption/desorption.

The mathematical analysis used in the present study aims at improving the modeling of the contactor system by considering radial and axial diffusion mechanisms, convection on the lumen side, and mass transfer across the porous membrane. The Knudsen and bulk diffusion mechanisms are assumed to represent mass transfer in the membrane pores. This model predicts results that are in better agreement with the experimental data than any previous mathematical analysis.

\section{MODEL DESCRIPTION}

A schematic of hollow fiber membrane contactor is shown 
in Fig. 1, which describes the flow pattern and various mass transfer steps taking place in the contactor system. Synthetic wastewater feed is passed through the lumen side of the contactor at a particular flow rate, while monoethanolamine is passed through the shell side in the counter flow direction. Both streams are recycled back to their respective original tanks. Gaseous molecules are desorbed from the lumen side to the shell side. Here they are assumed to instantaneously react with monoethanolamine as the latter is considered to be at a high concentration in the extract phase.

\section{A. Assumptions}

The mathematical model for the system makes the following assumptions:

1) Physical and transport conditions for the feed solution remain unchanged as the solution is dilute.

2) Isothermal operating conditions.

3) No wetting or swelling in the membrane, and pores are filled with air.

4) A Fully developed parabolic velocity profile is assumed on the lumen side. The operational experimental conditions for flow on the lumen side are chosen to be at very small Reynolds number.

5) The $\mathrm{pH}$ of the feed solution is controlled so that the gas remains in the molecular form.

6) The respective volumes of the feed and extract used in the process are very large in comparison to the volume of the membrane contactor.

7) An instantaneous reaction is assumed to occur on the shell side as the extract phase is highly concentrated.

\section{B. Governing Equations on the Lumen Side}

Transport of gas on the lumen side can be expressed by the unsteady-state convective-diffusive equation, which accounts for diffusion components in both the radial and axial directions and convection in the axial direction:

$$
\frac{\partial C_{l}}{\partial t}+v_{z} \frac{\partial C_{l}}{\partial z}=D_{l}\left(\frac{1}{r} \frac{\partial}{\partial r}\left(\frac{\partial C_{l}}{\partial r}\right)+\frac{\partial^{2} C_{l}}{\partial z^{2}}\right)
$$

Here, $C_{l}$ is the concentration of gas, and $D_{l}$ denotes the diffusivity of the gas in the aqueous feed solution. A fully developed parabolic velocity profile for laminar flow condition has been assumed on the lumen side of the contactor; therefore, $v_{z}$ can be defined as [12]:

$$
v_{z}(r)=2 \bar{V}\left[1-\left(\frac{r}{r_{1}}\right)^{2}\right]
$$

Here, $r_{l}$ is the inner radius of the fiber, and $\bar{V}$ is the average velocity of the fluid flowing on the lumen side that can be defined as:

$$
\bar{V}=\frac{Q}{N \pi r_{1}^{2}}
$$

The Feed flow rate and the number of fibers in the membrane contactor are denoted by $Q$ and $N$, respectively.

\section{Initial Condition (at $t=0$ )}

For all values of $r$ and $z$, i.e., $0<r<r_{l}$ and $0<z<L$ :

$$
C_{l}=C_{o, \text { in }}
$$

$C_{o, i n}$ is the initial concentration of gas in the feed solution.

\section{Boundary Conditions}

At $r=0$, for all values of $t$ and $z$, an axial symmetry condition can be applied:

$$
\left(\frac{\partial C_{l}}{\partial r}\right)_{r=0}=0
$$

At $z=0$, for all values of $r$ and $t$ :

$$
C_{l}=C_{\text {tank }}(t)
$$

For $z=L$, for all values of $r$ and $t$, it is assumed that diffusion of the gaseous species in the axial direction, at the outlet of the lumen side, becomes negligible in comparison to the bulk convection flow:

$$
D_{l}\left(\frac{\partial^{2} C_{l}}{\partial z^{2}}\right)=0
$$

At $r=r_{l}$, for all values of $z$ and $t$, the flux of the gas in the aqueous phase is equal to the flux of the gas diffusing through the pore [10]:

$$
\left.D_{l} \frac{\partial C_{l}}{\partial r}\right|_{r=r_{1}}=k_{g, \text { pore }}\left(\frac{p_{\mathrm{int}}^{g}-p_{b}^{g}}{R T}\right)
$$

According to our assumption that instantaneous reaction occurs on the shell side (i.e. ${p_{b}}^{g}=0$ ), the above equation reduces to:

$$
\left.D_{l} \frac{\partial C_{l}}{\partial r}\right|_{r=r_{1}}=k_{g, p o r e}\left(\frac{p_{\text {int }}^{g}}{R T}\right)
$$

At $r=r_{l}$, Henry's law can be applied (at the liquid-gas interface) [13]:

$$
p_{\text {int }}^{g}=H_{a} C_{l, \text { int }}
$$

Now, the mass transfer coefficient inside the pore can be estimated by using following equation [10]:

$$
k_{g, p o r e}=D_{c, p o r e}\left(\frac{\varepsilon}{\tau b}\right)
$$

Here, $\tau, \varepsilon, b$, and $D_{c \text {,pore }}$ denote the tortuosity of the pore, porosity of the membrane, thickness of the membrane, and combined diffusivity, respectively. As discussed earlier, the pores of the hydrophobic membrane are filled by air, and the transfer of gas can occur by either Knudsen flow or bulk diffusion, depending upon the ratio of the pore radius to the mean free path across the pore. In this study, we have assumed that both flows coexist; hence combined diffusivity can be obtained from the following correlation [13]:

$$
\frac{1}{D_{c, \text { pore }}}=\frac{1}{D_{k, \text { pore }}}+\frac{1}{D_{\text {air }}}
$$

Here, $D_{k, p o r e}$ is the Knudsen diffusivity and can be defined as: 
$D_{k, \text { pore }}=4850 d_{\text {pore }} \sqrt{\frac{T}{M_{w}}}$
The units of $D_{k, p o r e}$ are $\mathrm{cm}^{2} \cdot \mathrm{s}^{-1}$.

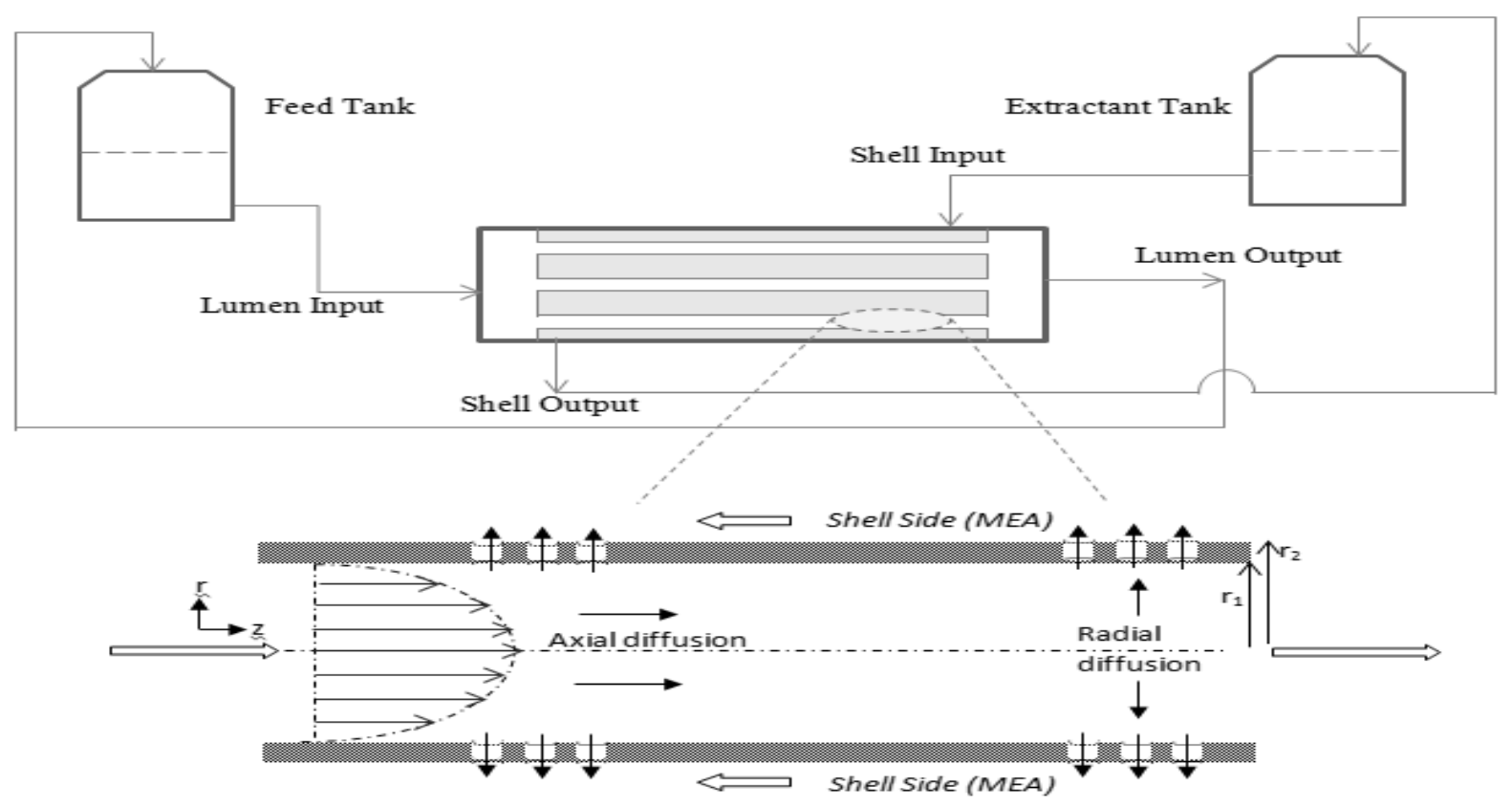

Fig. 1. Schematic representation of the process and various transport steps in the fiber module.

\section{A. Mass Balance across Feed Tank}

During the experiment, an aqueous feed solution is continuously recycled, and uniform mixing in the tank is assumed. The mass balance equation across the tank can be written as:

$$
V \frac{d C_{l, \text { tank }}}{d t}=Q\left(C_{l, \mathrm{z}=1}-C_{l, \text { tank }}\right)
$$

Here, $C_{l, \text { tank }}$ and $C_{l, z=l}$ denote the concentrations of gas in the tank and at the exit of the membrane contactor, respectively. $Q$ is the flow rate of feed solution, and $V$ is the volume of the aqueous solution.

The initial condition for $C_{l, t a n k}$ can be written as:

$$
\text { For } t=0 ; C_{l, \text { tank }}=C_{0}
$$

\section{TABLE I: PHYSICAI PARAMETERS FOR $\mathrm{H}_{2} \mathrm{~S}$ AT $298 \mathrm{~K}$}

\begin{tabular}{ll}
\hline Properties & Values \\
\hline Diffusivity in water, $\mathrm{D}_{l}\left(\mathrm{~cm}^{2} / \mathrm{s}\right)$ & $1.88 \times 10^{-5}$ \\
Diffusivity in air, $\mathrm{D}_{\text {air }}\left(\mathrm{cm}^{2} / \mathrm{s}\right)$ & 0.15 \\
Molecular weight of $\mathrm{H}_{2} \mathrm{~S}, \mathrm{M}_{\mathrm{W}}(\mathrm{g} / \mathrm{mol})$ & 34.08 \\
\hline
\end{tabular}

\section{TABLE II: SPECIFICATION OF LIQUI-CEL ${ }^{\circledR}$ MODULE}

\begin{tabular}{ll}
\hline Parameters & Values \\
\hline Porosity, $\varepsilon$ & 0.4 \\
Tortuosity factor for pore, $\tau$ & 2.54 \\
Inner diameter of fiber, $\mathrm{d}_{\mathrm{i}}(\mathrm{mm})$ & 0.24 \\
Outer diameter of fiber, $\mathrm{d}_{\mathrm{o}}(\mathrm{mm})$ & 0.3 \\
Effective fiber length, $\mathrm{L}(\mathrm{m})$ & 0.16 \\
Total number of fibers in contactor, $\mathrm{N}$ & 10,200 \\
Pore diameter, $\mathrm{d}_{\text {pore }}(\mathrm{nm})$ & 30 \\
Thickness of membrane, $b(\mu \mathrm{m})$ & 60 \\
Contact area, $\left(\mathrm{m}^{2}\right)$ & 1.4 \\
\hline
\end{tabular}

\section{B. Values of Parameters}

In this study, for modeling purposes, we have used the physical parameter values of $\mathrm{H}_{2} \mathrm{~S}$ to represent the acidic gas, which are given in Table I. The contactor parameters used in this analysis are also described in Table II.

\section{RESULTS AND DISCUSSIONS}

\section{A. Comparison between Experimental Results [11] and Simulated Results}

Agrahari et al. [11] obtained experimental results for the removal of $\mathrm{H}_{2} \mathrm{~S}$ from aqueous feed using Liqui-Cel ${ }^{\circledR}$ hollow fiber membrane contactor. In this study, the parameters of the same membrane contactor are used for solving the model. Fig. 2 compares the experimental and simulated results for the concentration variation and fractional removal of gas from the aqueous feed solution.

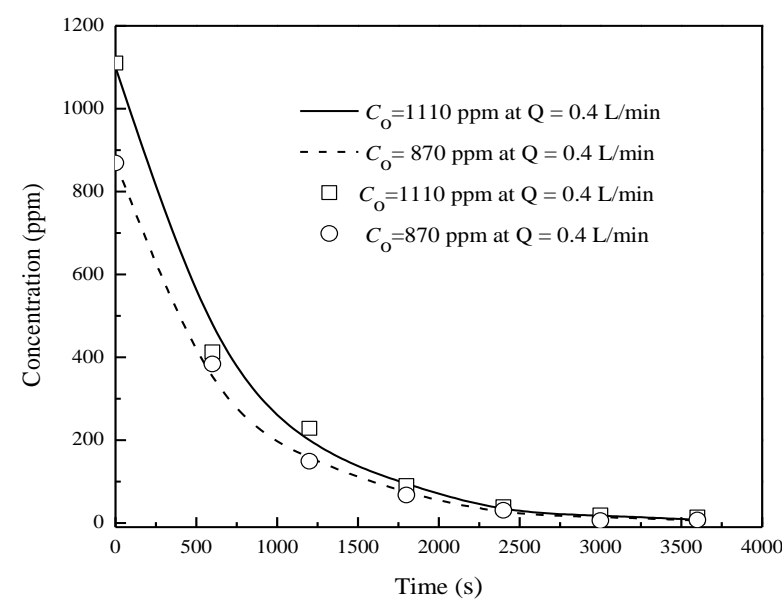

Fig. 2. Simulated and experimental results for variation in concentration of gas in aqueous feed solution with time 


\section{B. Influence of Feed Flow Rate on Concentration of Gas on Lumen Side}

Fig. 3 depicts the effect of increasing the feed flow rate on concentration variation with time. It can be observed from Fig. 3 that the rate of gas removal increases as the feed flow rate increases. This is evident because the increased convection on the lumen side leads to a lower viscous membrane resistance.

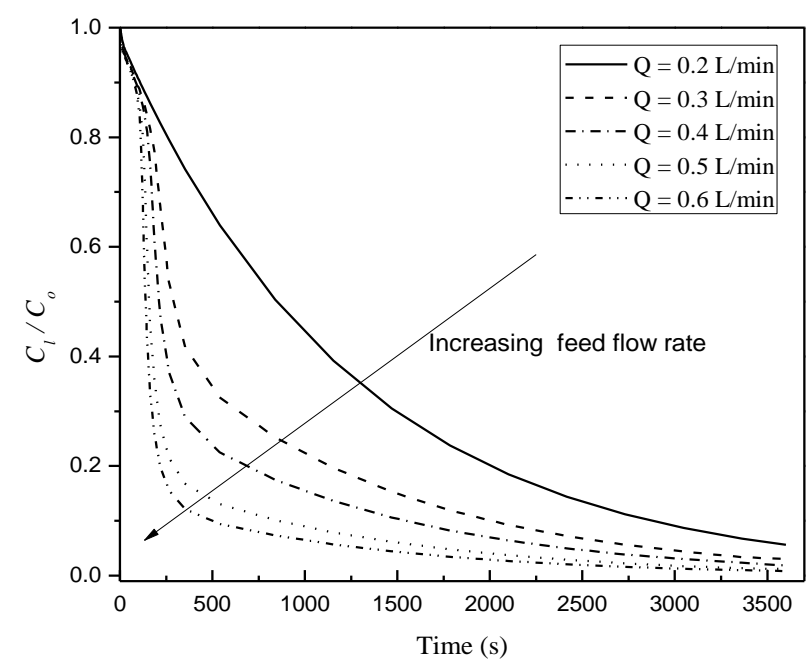

Fig. 3. Variation in fractional residual concentration of solution with $C_{0}=1100 \mathrm{ppm}$ with time for different feed flow rates

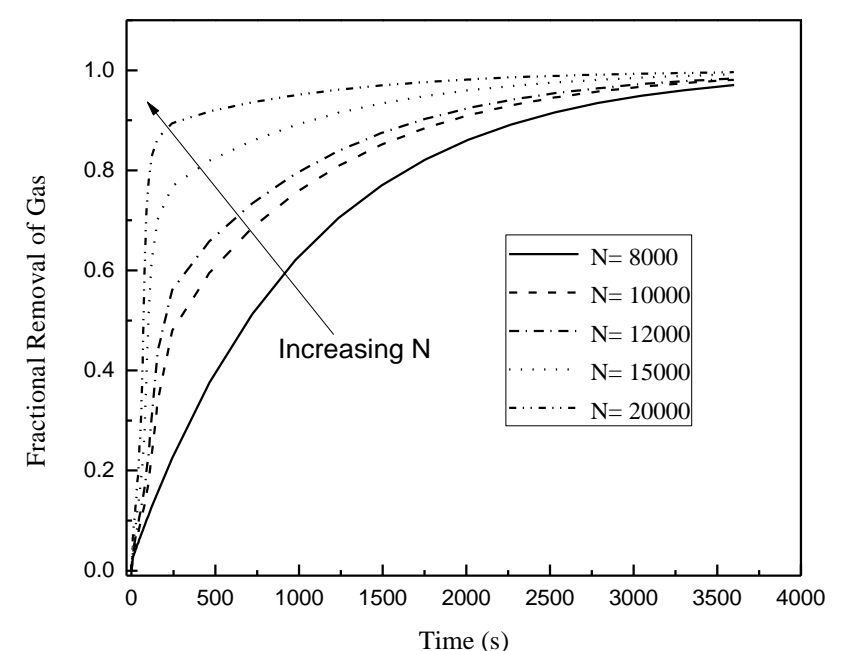

Fig. 4. Variation in fractional removal of gas with $C_{0}=1100 \mathrm{ppm} Q=0.4$ $\mathrm{L} / \mathrm{min}$ with time for different values of numbers of fibers

\section{Effect of Membrane Contactor Variables on Fractional Removal of Gas over Time}

\section{1) Number of fiber in contactor}

Fig. 4 illustrates the effect of the number of fibers on the fractional removal of gas, with the number of fibers ranging from 8,000 to 20,000 . It can be seen from the graph that the removal efficiency increases as the number of fibers increases. This is because the area of the porous membrane available for desorption also increases with an increase in the number of fibers.

\section{2) Effective lengths of fibers in contactor}

Fig. 5 depicts the effect of varying the lengths of fibers on the fractional removal of gas. It is observed that the gas removal becomes faster as length increases, because the area, from which the radial diffusion can occur, also increases for longer tubes. Further, above a certain value of $\mathrm{L}$, not much variation is observed because of the dilution of the feed solution.

\section{Variation in Concentration over Time at Different Axial Points}

Fig. 6 illustrates the variation in gas concentration over time at different points across the length of the lumen side.

As expected, the concentration of gas at the same time across the length of the lumen side is observed to be decreasing. This is because of the radial diffusion and subsequent transfer of gas molecules to the shell side between the two axial points.

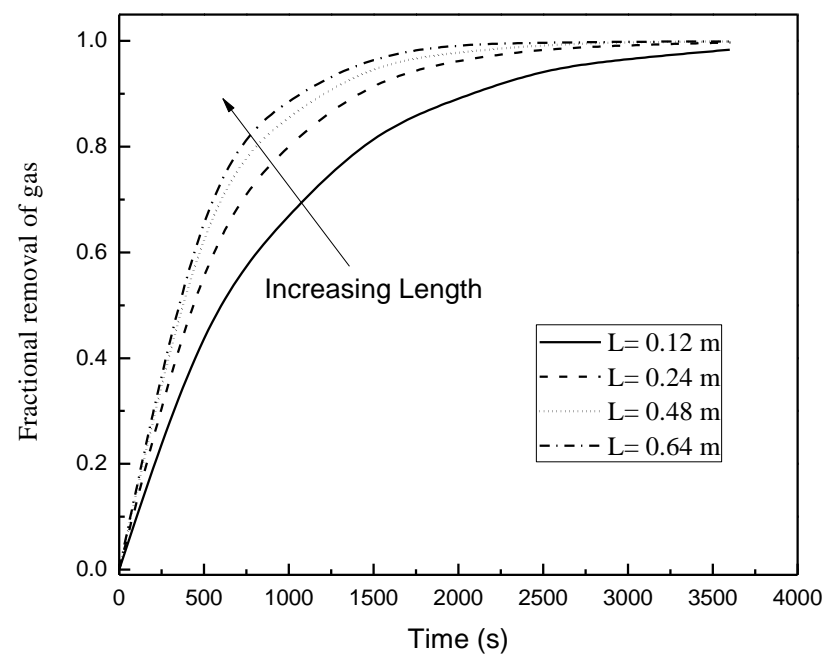

Fig. 5. Variation in fractional removal of gas with $C_{0}=1100 \mathrm{ppm} Q=0.4$ $\mathrm{L} / \mathrm{min}$ with time for different length of lumen fibers

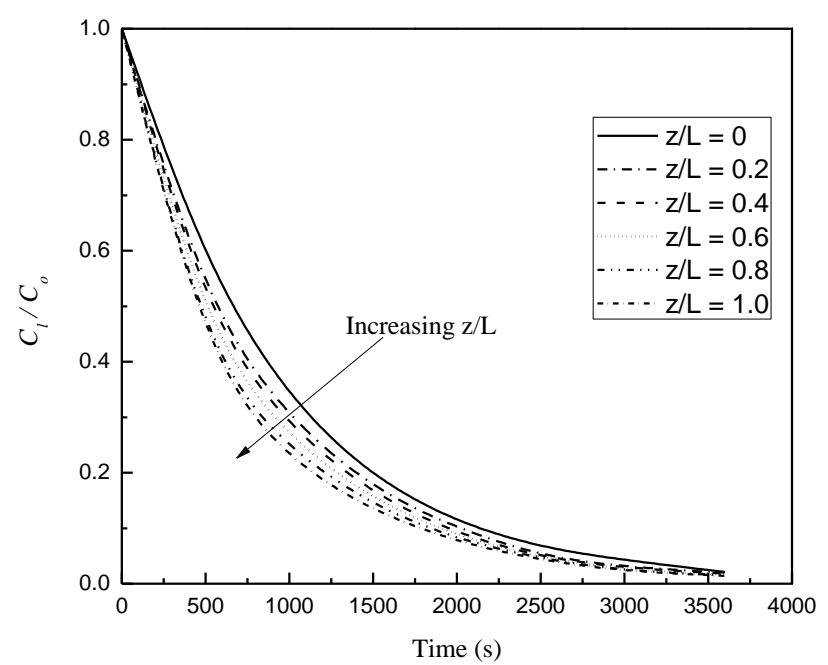

Fig. 6. Variation in fractional residual gas concentration with $C_{0}=1100$ and ppm $Q=0.4 \mathrm{~L} / \mathrm{min}$ with time for different points in axial direction

\section{CONCLUSION}

Degasification of water using a membrane contactor has been successfully analyzed, and the obtained results show an excellent agreement with the available experimental results. Further, the variation in the gas concentration in the aqueous feed solution over time has been obtained for different operating conditions such as feed flow rate and initial concentration. The effects of various parameters of the membrane contactor on the fractional removal of gas have 
also been discussed. In particular, it has been found that the degasification efficiency of the contactor increases with increase in the number of fibers and with the length of the lumen side.

\section{NOTATIONS}

$C_{o}$ Initial feed concentration (moles $/ \mathrm{m}^{3}$ )

$C_{l}$ Gas concentration on lumen side $\left(\mathrm{moles} / \mathrm{m}^{3}\right.$ )

$C_{l \text { tank }}$ Gas concentration in the tank (moles $/ \mathrm{m}^{3}$ )

$d_{\text {pore }}$ Diameter of pore $(\mathrm{m})$

$D_{c \text {,pore }}$ Combined diffusion coefficient $\left(\mathrm{m}^{2} / \mathrm{s}\right)$

$D_{l}$ Diffusion coefficient of gas in water $\left(\mathrm{m}^{2} / \mathrm{s}\right)$

$D_{k \text {,pore }}$ Knudsen diffusion coefficient of gas $\left(\mathrm{m}^{2} / \mathrm{s}\right)$

$D_{\text {air }}$ Diffusion coefficient of gas in air $\left(\mathrm{m}^{2} / \mathrm{s}\right)$

$H_{a}$ Henry's law constant $\left(\mathrm{Pa} . \mathrm{m}^{3} / \mathrm{mol}\right)$

$L$ Length of fiber (m)

$M_{W}$ Molecular weight of gas $(\mathrm{kg} / \mathrm{mol})$

$N$ Number of fibers in the Contactor module

$p_{\text {int }}{ }^{g}$ Partial pressure of gas at $r=r_{1}(\mathrm{~Pa})$

$p_{b}{ }^{g}$ Partial pressure of gas at $r=r_{2}(\mathrm{~Pa})$

$Q$ Feed flow rate $\left(\mathrm{m}^{3} / \mathrm{s}\right)$

$r$ Radial distance from the lumen-axis (m)

$r_{l}$ Inner radius of the lumen $(\mathrm{m})$

$r_{2}$ Outer radius of fiber $(\mathrm{m})$

$R$ Universal gas constant $(\mathrm{J} /(\mathrm{mol} . \mathrm{K}))$

$z$ Axial length (m)

$t$ Time (s)

$t_{0}$ Initial time (s)

$T$ Temperature (K)

$v_{z}$ Axial velocity on the lumen side $(\mathrm{m} / \mathrm{s})$

$V$ Volume of feed solution in the tank $\left(\mathrm{m}^{3}\right)$

$\varepsilon$ Porosity

$\tau$ Tortuosity factor for pore

$\bar{V}$ Average velocity on the lumen side $(\mathrm{m} / \mathrm{s})$

\section{REFERENCES}

[1] D. Hope, J. J. C. Dawson, M. S. Cresser, and M. F. Billett, "A method for measuring free $\mathrm{CO}_{2}$ in upland streamwater using headspace analysis," Journal of Hydrology, vol. 166, pp. 1-14, 1995.

[2] M. I. Leybourne, I. D. Clark, and W. D. Goodfellow, "Stable isotope geochemistry of ground and surface waters associated with undisturbed massive sulfide deposits; constraints on origin of waters and water-rock reactions," Chemical Geology, vol. 231, pp. 300-325, 2006.

[3] B. B. Joergensen, "The sulfur cycle of freshwater sediments: role of thiosulfate, Lirnnol," Oceanography, vol. 35, pp. 1329-1342, 1990.

[4] E. Vaiopoulou, P. Melidis, and A. Aivasidis, "Sulfide removal in wastewater from petrochemical industries by autotrophic denitrification," Water Research, vol. 39, pp. 4101-4109, 2005.

[5] S. T. Summerfelt, B. J. Vinci, and R. H. Piedrahita, "Oxygenation and carbon dioxide control in water reuse systems," Aquacultural Engineering, vol. 22, pp. 87-108, 2000.

[6] A. Bottino, G. Capannelli, A. Comite, R. D. Felice, and R. Firpo, " $\mathrm{CO}_{2}$ removal from a gas stream by membrane contactor," Separation and Purification Technology, vol. 59, pp. 85-90, 2008.

[7] G. K. Agrahari, N. Verma, and P. K. Bhattacharya, "Application of hollow fiber membrane contactor for the removal of carbon dioxide from water under liquid-liquid extraction mode," Journal of Membrane Science, vol. 375, pp. 323-333, 2011.
[8] P. Keshavarz, J. Fathikalajahi, and S. Ayatollahi, "Mathematical modeling of the simultaneous absorption of carbon dioxide and hydrogen sulfide in a hollow fiber membrane contactor," Separation and Purification Technology, vol. 63, pp. 145-155, 2008

[9] C. I. Dermott, S. A. Tarafder, O. Kolditz, and C. Schüth, "Vacuum assisted removal of volatile to semi volatile organic contaminants from water using hollow fiber membrane contactors: II: A hybrid numerical-analytical modeling approach," Journal of Membrane Science, vol. 282, pp. 17-28, 2007.

[10] A. Mandowara and P. K. Bhattacharya, "Membrane contactor as degasser operated under vacuum for ammonia removal from water: A numerical simulation of mass transfer under laminar flow conditions," Computers and Chemical Engineering, vol. 33, pp. 1123-1131, 2009.

[11] G. K. Agrahari, A. Rawat, N. Verma, and P. K. Bhattacharya, "Removal of dissolved $\mathrm{H}_{2} \mathrm{~S}$ from wastewater using hollow fiber membrane contactor: Experimental and mathematical analysis," Desalination, vol. 314, pp. 34-42, 2013.

[12] H. Kreulen, C. A. Smolders, G. F. Versteeg, and W. P. M. V. Swaaij, "Microporous hollow fibre membrane modules as gas-liquid contactors. Part 1. Physical mass transfer processes: A specific application: Mass transfer in highly viscous liquids," Journal of Membrane Science, vol. 78, pp. 197-216, 1993.

[13] A. Mandowara and P. K. Bhattacharya, "Simulation studies of ammonia removal from water in a membrane contactor under liquideliquid extraction mode," Journal of Environmental Management, vol. 92, pp. 121-130, 2011

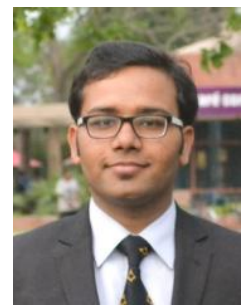

Ashutosh Rawat is a final year student of the integrated B.Tech-M.Tech dual degree program in the department of chemical engineering at Indian Institute of Technology, Kanpur, India. His research interests include membrane science, simulation and modeling, separation processes and fuel cell. He is currently working on mathematical and simulation studies of proton exchange membrane fuel cells.

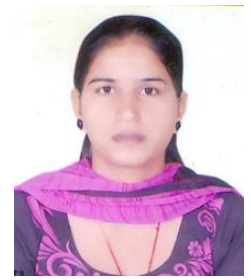

Niharika Pandey obtained her masters in environmental science from CSJM University Kanpur, India in the year 2012. Currently she is working as research associate in the chemical Engineering Department at Indian Institute of Technology Kanpur, India. Her research interests include membrane science and separation.

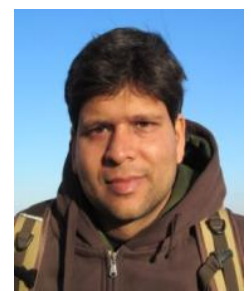

Gunjan K. Agrahari obtained his $\mathrm{PhD}$ in Chemical Engineering from Indian Institute of Technology Kanpur, India in the year 2013. Currently he is working as researcher in Department of Chemical Engineering, Indian Institute of Technology Kanpur. His research interests include membrane contactor applications, wastewater treatment, and vapor-liquid equilibrium studies.

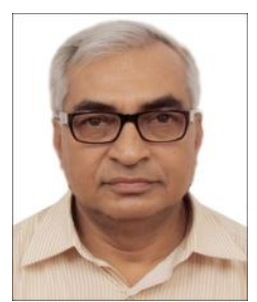

Prashant K. Bhattacharya is a senior professor in the Chemical Engineering Department at Indian Institute of Technology Kanpur, India. His research expertise is predominantly in the industrially important and scientifically vibrant area of membrane separations. His current research interests and important contributions are in the field of membranes, nano and ultrafiltration, pervaporation; industrial and municipal waste treatment, pulping, environmental pollution control, novel membrane materials, fuel cell and their characterization. 